\title{
PENERAPAN FUZZY TSUKAMOTO UNTUK MENENTUKAN JUMLAH PRODUKSI RAKIK
}

\author{
Eka Praja Wiyata Mandala ${ }^{{ }^{*}}$, Dewi Eka Putri ${ }^{1}$ \\ ${ }^{1}$ Teknik Informatika, Universitas Putra Indonesia YPTK Padang \\ email:ekaprajawm@upiyptk.ac.id ${ }^{1}$,dewieka@upiyptk.ac.id ${ }^{1}$
}

\begin{abstract}
The home industry, especially in the culinary sector, has grown in recent years. Many business actors produce the same products as other business actors, so competition often occurs. One of them is the Usaha Rakik Julidar which since 25 years ago made and sold rakik. There are so many types of rakik that there are minimarkets with different business actors. This makes the rakik not sold out at the convenience store and has an effect on the amount of production. This research was conducted to assist the Usaha Rakik Julidar in predicting the amount of production using Fuzzy Tsukamoto inference method. This research creates a web-based application to help predict the amount of production by looking at incoming demand and the number of workers available. From the prediction results with Fuzzy Tsukamoto, if the demand is 125 packs and the number of workers is 35 people, then the total production to be done is 140 packs. By obtaining a clear amount of production, this application really helps Usaha Rakik Julidar in maximizing production.
\end{abstract}

Keywords: fuzzy tsukamoto; prediction; production; rakik

\begin{abstract}
Abstrak: Industri rumah tangga khususnya di sektor kuliner banyak tumbuh dalam beberapa tahun terakhir. Banyak pelaku usaha menghasilkan produk yang sama dengan pelaku usaha lainnya, sehingga sering terjadi persaingan. Salah satunya adalah Usaha Rakik Julidar yang sejak 25 tahun yang lalu membuat dan menjual rakik. Banyak sekali jenis Rakik yang ada minimarket dengan pelaku usaha yang berbeda. Hal ini membuat rakik tidak terjual habis di minimarket dan berpengaruh pada jumlah produksi. Penelitian ini dilakukan untuk membantu Usaha Rakik Julidar dalam melakukan prediksi jumlah produksi dengan menggunakan metode inferensi fuzzy Tsukamoto. Penelitian ini membuat aplikasi berbasis web untuk membantu melakukan prediksi jumlah produksi dengan melihat permintaan yang masuk dan jumlah pekerja yang tersedia. Dari hasil prediksi dengan fuzzy Tsukamoto, jika permintaan sebanyak 125 bungkus dan jumlah tenaga kerja 35 orang, maka jumlah produksi yang harus dilakukan adalah 140 bungkus. Dengan diperolehnya jumlah produksi yang jelas, aplikasi ini sangat membantu Usaha Rakik Julidar dalam memaksimalkan produksi.
\end{abstract}

Kata kunci: fuzzy tsukamoto; prediksi; produksi; rakik 
DOI: https://doi.org/10.33330/jurteksi.v8i1.665

Available online at http://jurnal.stmikroyal.ac.id/index.php/jurteksi

\section{PENDAHULUAN}

Rakik atau dalam bahasa Indonesia bisa juga disebut rempeyek, merupakan makanan khas dari daerah Sumatera Barat yang memiliki cita rasa yang enak dan unik. Rakik diproduksi secara tradisional menggunakan tangan dan bebas dari bahan pengawet. Rakik bisa dimakan sebagai camilan atau sebagai lauk untuk makan nasi.

Rakik atau rempeyek merupakan makanan atau penganan yang terbuat dari adonan tepung beras dan tepung tapioka dengan campuran kacang dan dimasak dengan digoreng [1].

Usaha rakik sebagian besar diproduksi oleh industri rumah tangga dimana masuk ke dalam kategori usaha kecil dan menengah (UMKM). Namun saat ini, produsen rakik sudah banyak melakukan produksi dengan skala besar dan menyalurkannya secara luas [2].

Di Kota Padang khususnya, banyak sekali UMKM yang menggeluti usaha pembuatan rakik ini. Salah satu UMKM yang memproduksi rakik adalah Rakik Julidar yang terletak di Kelurahan Kapalo Koto Kota Padang. Usaha Rakik Julidar didirikan oleh Ibu Julidar sejak 25 tahun yang lalu [3].

Usaha Rakik Julidar merupakan industri rumah tangga yang khusus memproduksi rakik. Produksi dilakukan setiap hari mulai dari pengolahan bahan baku, proses produksi sampai proses pengemasan. Penyaluran rakik dilakukan setiap awal minggu ke beberapa toko dan minimarket yang ada di Kota Padang.

Proses produksi dibantu oleh beberapa orang tetangga yang diminta bantuan sebagai tenaga kerja. Tetangga yang terlibat dalam proses produksi tidak selalu sama setiap harinya, bisa lebih banyak atau lebih sedikit, tergantung dari kebutuhan pemilik usaha rakik.
Produksi dilakukan tergantung dari banyaknya permintaan yang masuk dari toko dan minimarket langganan dan jumlah tenaga kerja yang terlibat.

Alasan kenapa penelitian ini dilakukan adalah angka produksi rakik di Usaha Rakik Julidar sering tidak tercapai karena banyaknya permintaan yang masuk, tetapi jumlah tenaga kerja yang terlibat hanya sedikit. Hal ini juga terjadi sebaliknya, disaat permintaan sedikit, tenaga kerja yang tersedia banyak, sehingga masalah ini akan mengganggu dalam penentuan angka produksi rakik. Hal ini juga untuk membantu Ibu Julidar dalam menentukan jumlah produksi yang tepat, agar permintaan dapat terpenuhi.

Tujuan dari penelitian ini adalah menghasilkan sebuah aplikasi yang dapat membantu Usaha Rakik Julidar untuk menentukan jumlah produksi yang tepat setiap minggunya sebelum disalurkan ke beberapa toko dan minimarket.

Pada penelitian sebelumnya, terdapat masalah yang muncul pada saat produksi rempeyek dilakukan. Penelitian ini dilakukan di Usaha Ibu Lilis Kecamatan Pacet Kabupaten Cianjur Jawa Barat. Masalah yang terjadi adalah adanya ketidak konsistenan ukuran produk rempeyek yang dibuat sehingga mengakibatkan berat per bungkus berbeda-beda. Solusi yang diberikan adalah penggunaan alat presser untuk mencetak rempeyek agar mempunyai ukuran yang sama [4].

Pada penelitian lainnya yang dilakukan pada PKBM Sari Ilmu di Kabupaten Bantul, masalah yang muncul berkaitan dengan produksi rempeyek adalah kurangnya tenaga kerja yang terlibat pada produksi rempeyek, sehingga pada saat produk rempeyek habis terjual, PKBM Sari Ilmu tidak bisa langsung melakukan produksi dan memenuhi permintaan berikutnya [5]. 
Penelitian lain berikutnya yang juga membahas produksi rempeyek dilakukan pada beberapa agroindustri UMKM di Propinsi Jambi. Penelitian ini mengangkat masalah yaitu sulitnya memperoleh bahan baku untuk pembuatan rempeyek karena harga yang tidak stabil dan persaingan antar pengusaha penyedia bahan baku pembuatan rempeyek [6].

Untuk menentukan jumlah produksi rakik pada Usaha Rakik Julidar akan digunakan pendekatan fuzzy. Fuzzy adalah hasil generalisasi dari logika yang mempunyai dua nilai keanggotaan, yaitu 0 dan 1. Artinya suatu pernyataan berada antara benar sampai dengan salah [7].

Fuzzy Tsukamoto merupakan penggabungan aturan sesuai dengan data yang sudah tersedia, dimana setiap aturan akan direpresentasikan menggunakan himpunan fuzzy, yang mempunyak fungsi keanggotaan. Langkah fuzzy dimulai dari proses fuzzyfikasi yang merubah nilai tegas menjadi nilai linguistic, dilanjutkan dengan pembentukan rule dari semua kemungkinan yang terjadi, kemudian diproses dengan mesin inferensi Tsukamoto untuk memperoleh nilai output, dan terakhir dilakukan proses defuzzyfikasi yaitu merubah menjadi nilai tegas kembali [8].

Penelitian tentang fuzzy dilakukan di Bayang Pesisir Selatan pada UD. Tempe Puji. Penelitian ini dilakukan untuk memperoleh jumlah produksi tempe yang diproduksi oleh industri rumah tangga. Penelitian ini menggunakan teknik inferensi metode Tsukamoto dan menghasil aplikasi yang dapat membantu UD Tempe Puji dalam menentukan jumlah produksi [9].

Penelitian lainnya tentang fuzzy Tsukamoto pernah juga dilakukan pada UKM Abadi untuk memprediksi produksi tahu. Penelitian ini menggunakan variabel input persediaan dan permintaan untuk memperoleh variabel output yaitu produksi. Penelitian ini menghasilkan aplikasi berbasis web untuk membantu UKM Abadi dalam memprediksi jumlah produksi tahu [10].

Penelitian yang dilakukan di Usaha Rakik Julidar ini, akan dibuat sebuah aplikasi berbasis web untuk membantu dalam menentukan jumlah produksi rakik. Aplikasi yang dihasilkan pada penelitian ini dibuat dengan bahasa pemrograman server yaitu PHP dan menggunakan basis data server MySQL sebagai penyimpanan data [11].

\section{METODE}

Penelitian dilakukan dengan menerapkan metode penelitian yang memiliki kerangka penelitian seperti berikut :

1. Melakukan identifikasi masalah

Masalah pada penelitian ini diperoleh dengan cara melakukan observasi langsung ke Usaha Rakik Julidar.

2. Mengumpulkan data

Data diperoleh setalah melakukan observasi langsung dan kemudian dilakukan wawancara dengan Ibu Julidar sebagai pemilik usaha. Data yang diperoleh dalam bentuk jumlah adonan bahan baku, jumlah tenaga kerja dan jumlah produksi rakik selama 3 bulan terakhir.

3. Melakukan analisis data

Data yang sudah diperoleh dari Ibu Julidar, kemudian dilakukan analisis dengan menggunakan metode inferensi Fuzzy Tsukamoto.

4. Merancang prototipe aplikasi

Setelah analisis data selesai, dilakukan perancangan protoipe aplikasi fuzzy berupa rancangan antar 
muka dari aplikasi.

5. Implementasi menjadi aplikasi

Dilakukan proses pengodingan untuk menghasilkan aplikasi yang bisa digunakan sesuai dengan prototipe yang sudah dirancang sebelumnya.

6. Menarik kesimpulan

Langkah terakhir dari penelitian ini adalah proses penarikan kesimpulan dari semua proses penelitian yang sudah dilakukan.

Langkah-langkah dari fuzzy Tsukamoto adalah sebagai berikut :

1. Fuzzifikasi

Merupakan proses perubahan variabel numerik menjadi variabel linguistik.

2. Pembentukan Aturan

Aturan diperoleh dari orang yang ahli di dalam kasus yang akan diselesaikan dengan fuzzy tersebut

3. Mesin Inferensi

Menggunakan fungsi implikasi min untuk mendapatkan nilai $\alpha$ predikat.

4. Defuzzifikasi
Proses menerjemahkan himpunan nilai keluaran kedalam nilai yang tegas.

\section{HASIL DAN PEMBAHASAN}

Proses produksi rakik pada Usaha Rakik Julidar dilakukan setiap hari dimulai dari proses pembuatan adonan, pencetakan, penggorengan sampai pada pengemasan. Pengemasan rakik terdiri dari 25 keping rakik yang dibungkus plastik. Proses produksi dibantu oleh beberapa orang tenaga kerja dari tetangga yang berbeda jumlahnya setiap hari. Setiap awal minggu, rakik yang sudah dikemas, akan disalurkan ke beberapa toko dan minimarket di Kota Padang.

Data produksi diperoleh langsung dari hasil wawancara dan data tertulis dari Usaha Rakik Julidar. Data yang diolah yaitu data produksi selama 3 bulan terakhir, yaitu bulan Maret sampai Mei 2020 yang dibagi menjadi 12 minggu. Data produksi dapat dilihat pada Tabel 1.

Tabel 1. Data Produksi Usaha Rakik Julidar

\begin{tabular}{ccccc}
\hline \multirow{3}{*}{ Bulan } & Minggu & $\begin{array}{c}\text { Permintaan } \\
\text { per minggu } \\
\text { (Bungkus) }\end{array}$ & $\begin{array}{c}\text { Tenaga kerja } \\
\text { per minggu } \\
\text { (Orang) }\end{array}$ & $\begin{array}{c}\text { Jumlah Produksi } \\
\text { per minggu } \\
\text { (Bungkus) }\end{array}$ \\
\hline \multirow{4}{*}{ Maret 2020 } & I & 140 & 35 & 140 \\
\cline { 2 - 5 } & II & 130 & 31 & 132 \\
\cline { 2 - 5 } & III & 145 & 42 & 158 \\
\hline \multirow{4}{*}{ April 2020 } & IV & 120 & 28 & 125 \\
\cline { 2 - 5 } & I & 148 & 33 & 151 \\
\cline { 2 - 5 } & II & 137 & 40 & 140 \\
\cline { 2 - 5 } & III & 123 & 34 & 130 \\
\hline \multirow{3}{*}{ Mei 2020 } & IV & 141 & 36 & 152 \\
\cline { 2 - 5 } & I & 118 & 37 & 128 \\
\cline { 2 - 5 } & II & 142 & 30 & 134 \\
\cline { 2 - 5 } & III & 148 & 29 & 122 \\
\hline
\end{tabular}


Dari Tabel 1, dapat dilihat bahwa data yang diperoleh berupa data selama 12 minggu mulai dari bulan Maret sampai Mei 2020 yang terdiri dari rekapitulasi permintaan per minggu (bungkus), rekapitulasi tenaga kerja yang telibat per minggu (orang) dan rekapitulasi jumlah produksi per minggu (bungkus).

Data permintaan paling banyak terdapat pada minggu I April 2020 yaitu 148 bungkus sedangkan permintaan paling sedikit pada minggu IV Mei 2020 yaitu 110 bungkus. Sementara tenaga kerja paling banyak terdapat pada minggu III Maret 2020 yaitu 42 orang dan tenaga kerja paling sedikit terdapat pada minggu IV Maret 2020 yaitu 28 orang.

Data jumlah produksi terbanyak terdapat pada minggu III Maret 2020 yaitu 158 bungkus dan produksi paling sedikit pada minggu III Mei 2020 yaitu 122 bungkus.

Untuk membantu Usaha Rakik Julidar dalam menentukan jumlah produksi dengan menggunakan pendekatan fuzzy maka perlu ditentukan terlebih dahulu variabel input dan variabel output. Variabel fuzzy akan memiliki semesta pembicaraan yaitu batas minimal sampai dengan batas maksimal dari variabel fuzzy. Selain itu, variabel fuzzy juga akan memiliki himpunan fuzzy yang juga akan memiliki batas minimal dan batas maksimal yang disebut dengan domain himpunan fuzzy. Penjelasan secara rinci dapat dilihta pada Tabel 2.

Tabel 2 menunjukkan permintaan dan tenaga kerja sebagai variabel input dan produksi sebagai variabel output. Permintaan berada diantar 110 s/d 148 bungkus, sementara tenaga kerja berada diantara $28 \mathrm{~s} / \mathrm{d} 42$ orang, dan produksi berada diantara 122 s/d 158 bungkus. Masing-masing variabel fuzzy memiliki himpunan fuzzy, permintaan naik dengan domain 130 s/d 148 bungkus dan permintaan turun dengan domain $110 \mathrm{~s} / \mathrm{d}$ 129 bungkus, tenaga kerja banyak dengan domain $36 \mathrm{~s} / \mathrm{d} 42$ orang dan tenaga kerja sedikit dengan domain 28 s/d 35 orang, sedangkan produksi meningkat dengan domain 141 s/d 158 bungkus dan produksi menurun dengan domain $122 \mathrm{~s} / \mathrm{d} 140$ bungkus.

Jika untuk minggu I Juni 2020 diketahui permintaan yang masuk sebanyak 125 bungkus dan jumlah tenaga kerja yang tersedia 35 orang, berapa jumlah produksi untuk minggu I Juni 2020 tersebut?

Tahap pertama dimulai dari tahap fuzzyfikasi yaitu proses untuk mendapatkan nilai derajat keanggotaan $(\mu)$ dari himpunan fuzzy.

Tabel 2. Variabel Fuzzy

\begin{tabular}{|c|c|c|c|c|}
\hline Variabel & Variabel Fuzzy & $\begin{array}{c}\text { Semesta } \\
\text { Pembicaraan }\end{array}$ & $\begin{array}{l}\text { Himpunan } \\
\text { Fuzzy }\end{array}$ & $\begin{array}{c}\text { Domain } \\
\text { Himpunan Fuzzy }\end{array}$ \\
\hline \multirow{4}{*}{ Input } & \multirow{2}{*}{ Permintaan } & \multirow{2}{*}{$110-148$} & Naik & $130-148$ \\
\hline & & & Turun & $110-129$ \\
\hline & \multirow{2}{*}{ Tenaga Kerja } & \multirow{2}{*}{$28-42$} & Banyak & $36-42$ \\
\hline & & & Sedikit & $28-35$ \\
\hline \multirow{2}{*}{ Output } & \multirow{2}{*}{ Produksi } & \multirow{2}{*}{$122-158$} & Meningkat & $141-158$ \\
\hline & & & Menurun & $122-140$ \\
\hline
\end{tabular}


a. Permintaan (x), memiliki himpunan fuzzy NAIK dan TURUN.

$\mu$ PermintaanNAIK[125]

$$
\begin{aligned}
& =(125-110) /(148-110) \\
& =0,395
\end{aligned}
$$

$\mu$ PermintaanTURUN[125]

$$
\begin{aligned}
& =(148-125) /(148-110) \\
& =0,605
\end{aligned}
$$

Perhitungan diatas dapat digambarkan dalam kurva linier naik dan linier turun seperti pada Gambar 1.

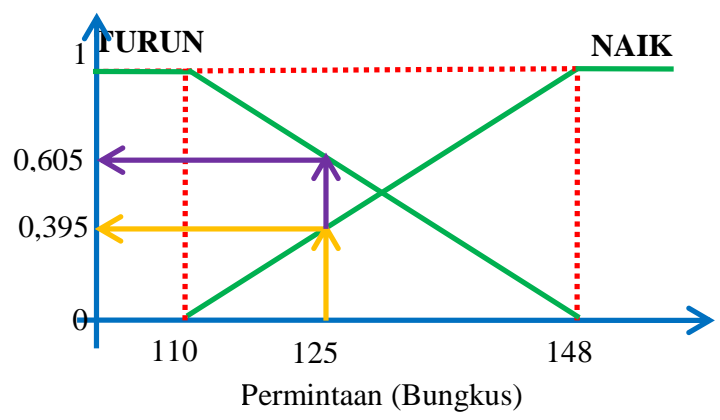

Gambar 1. Kurva Linier Permintaan

b. Tenaga Kerja (y), punya himpunan fuzzy BANYAK dan SEDIKIT. $\mu$ TenagaKerjaBANYAK[35]

$$
\begin{aligned}
& =(35-28) /(42-28) \\
& =0,500
\end{aligned}
$$

$\mu$ TenagaKerjaSEDIKIT[35]

$$
\begin{aligned}
& =(42-35) /(42-28) \\
& =0,500
\end{aligned}
$$

Perhitungan diatas dapat digambarkan dalam kurva linier naik dan linier turun seperti pada Gambar 2.

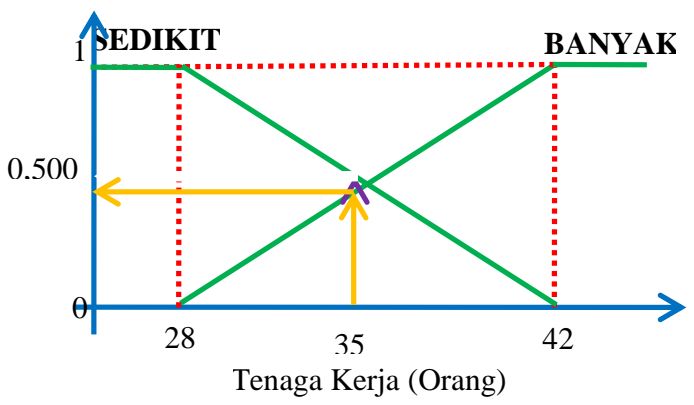

Gambar 2. Kurva Linier Tenaga Kerja

c. Produksi (z), punya himpunan fuzzy

$$
\begin{aligned}
& \text { MENINGKAT dan MENURUN. } \\
& \mu \text { ProduksiMENINGKAT[z] } \\
& \quad=(\mathrm{z}-122) /(158-122) \\
& \mu \text { ProduksiMENURUN[z] } \\
& \quad=(158-\mathrm{z}) /(158-122)
\end{aligned}
$$

Tahap kedua merupakan proses pembentukan aturan-aturan dengan empat kemungkinan aturan yang akan digunakan yaitu :

1. IF Permintaan NAIK AND Tenaga Kerja BANYAK THEN Produksi MENINGKAT

2. IF Permintaan TURUN AND Tenaga Kerja BANYAK THEN Produksi MENINGKAT

3. IF Permintaan NAIK AND Tenaga Kerja SEDIKIT THEN Produksi MENURUN

4. IF Permintaan TURUN AND Tenaga Kerja SEDIKIT THEN Produksi MENURUN

Tahap ketiga adalah penggunaan mesin inferensi Tsukamoto dengan menggunakan fungsi implikasi MIN untuk memperoleh nilai $\alpha$-predikat yang digunakan untuk menghitung nilai tegas. [R1] IF Permintaan NAIK AND Tenaga Kerja BANYAK THEN Produksi MENINGKAT

$$
\begin{aligned}
& \alpha \text {-pred } 1=\mu \mathrm{NAIK} \cap \mu \mathrm{BANYAK} \\
& =\min (\mu \mathrm{NAIK}[125], \mu \mathrm{BANYAK}[35]) \\
& =\min (0,395 ; 0,500) \\
& \alpha \text {-pred } 1=0,395
\end{aligned}
$$

Lihat himpunan MENINGKAT pada grafik keanggotaan Produksi

$$
\begin{aligned}
(\mathrm{z} 1-122) /(158-122) & =0,395 \\
\mathrm{z} 1 & =136,211
\end{aligned}
$$

[R2] IF Permintaan TURUN AND Tenaga Kerja BANYAK THEN Produksi MENINGKAT $\alpha$-pred $2=\mu$ TURUN $\cap \mu$ BANYAK $=\min (\mu \mathrm{TURUN}[125], \mu \mathrm{BANYAK}[35])$ 
DOI: https://doi.org/10.33330/jurteksi.v8i1.665

Available online at http://jurnal.stmikroyal.ac.id/index.php/jurteksi

$=\min (0,605 ; 0,500)$

$\alpha$-pred $2=0,500$

Lihat himpunan MENINGKAT pada grafik keanggotaan Produksi

$$
\begin{aligned}
(\mathrm{z} 2-122) /(158-122) & =0,500 \\
\mathrm{z} 2 & =140
\end{aligned}
$$

[R3] IF Permintaan NAIK AND Tenaga Kerja SEDIKIT THEN Produksi MENURUN

$\alpha$-pred3 $=\mu$ NAIK $\cap \mu$ SEDIKIT

$=\min (\mu \mathrm{NAIK}[125], \mu \mathrm{SEDIKIT}[35])$

$=\min (0,395 ; 0,500)$

$\alpha$-pred3 $=0,395$

Lihat himpunan MENURUN pada grafik keanggotaan Produksi

$$
\begin{aligned}
(158-\mathrm{z} 3) /(158-122) & =0,395 \\
\mathrm{z} 3 & =143,789
\end{aligned}
$$

[R4] IF Permintaan TURUN AND Tenaga Kerja SEDIKIT THEN Produksi MENURUN

$\alpha$-pred $4=\mu$ TURUN $\cap \mu$ SEDIKIT

$=\min (\mu \mathrm{TURUN}[125], \mu$ SEDIKIT[35])

$=\min (0,605 ; 0,500)$

$\alpha$-pred $4=0,500$

Lihat himpunan MENURUN pada grafik keanggotaan Produksi

$$
\begin{aligned}
(158-\mathrm{z} 4) /(158-122) & =0,500 \\
\mathrm{z} 4 & =140
\end{aligned}
$$

Tahap paling akhir dalam fuzzy adalah proses defuzzyfikasi dengan menggunakan metode rata-rata (average), yaitu proses merubah menjadi nilai tegas kembali.

$$
\begin{aligned}
& z=\frac{\sum_{i=1}^{n}\left(\text { apred }_{i} * Z_{i}\right)}{\sum_{i=1}^{n} \text { apred }_{i}} \\
& z=\frac{53,767+70+56,759+70}{1,790} \\
& z=\frac{250,526}{1,790}=139,958=140
\end{aligned}
$$

Jadi, untuk minggu I Juni 2020 dengan jumlah permintaan 125 bungkus dan jumlah tenaga kerja yang terlibat 35 orang, maka jumlah produksi yang harus dilakukan oleh Usaha Rakik Julidar adalah 140 bungkus.

Untuk memudahkan Ibu Julidar dalam melakukan prediksi produksi rakik, penelitian ini menghasilkan aplikasi prediksi dengan menggunakan Fuzzy Tsukamoto yang berbasis web. Aplikasi ini bisa bisa diakses kapanpun dan dimanapun. Ibu Julidar harus melakukan login sebelum bisa mengakses aplikasi ini seperti Gambar 3

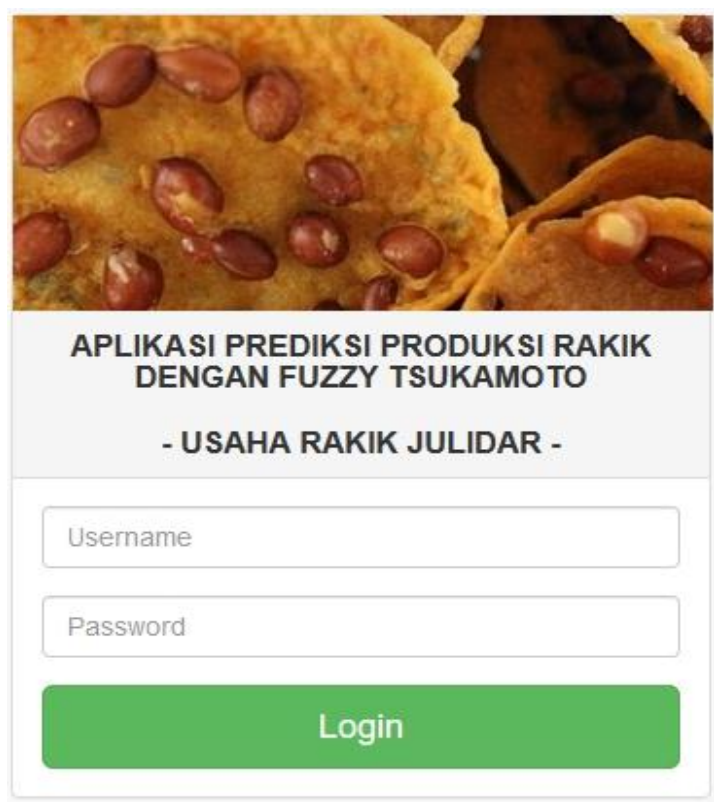

Gambar 3. Halaman Login

Gambar 3 adalah halaman pertama yang diakses. Pemilik usaha harus memasukkan username dan password sebelum mengakses semua fitur dalam aplikasi ini. Setelah login berhasil, akan diarahkan ke halaman utama seperti Gambar 4. 


\section{Dashboard}

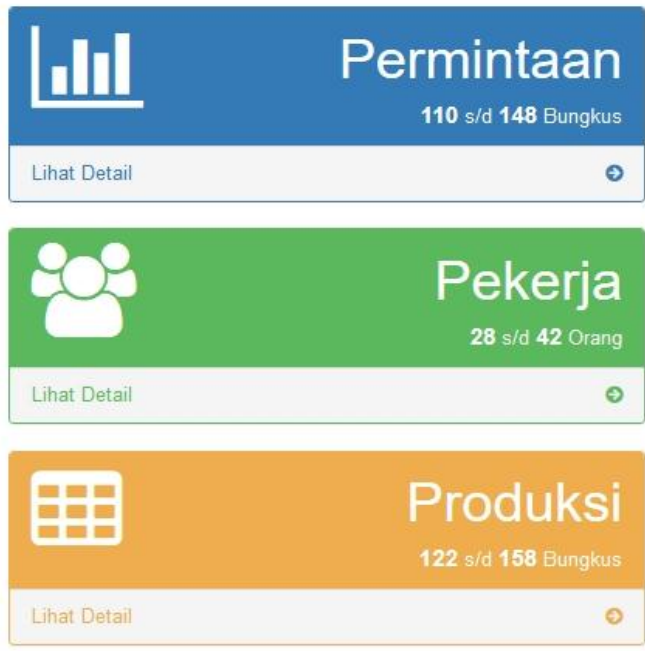

Gambar 4. Informasi Halaman Utama

Gambar 4 memberikan informasi tentang rentang permintaan, rentang tenaga kerja dan rentang produksi dari data yang diperoleh dari Usaha Rakik Julidar untuk digunakan dalam proses fuzzy Tsukamoto. Di halaman utama juga terdapat kurva seperti Gambar 5.

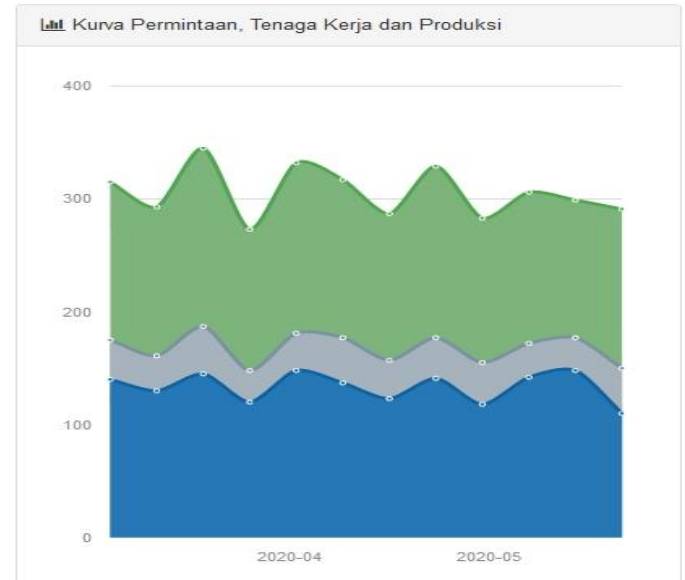

Gambar 5. Kurva Pemintaan, Tenaga Kerja dan Produksi

Gambar 5 adalah kurva dari semua data yang akan diolah, kurva bawah adalah permintaan, kurva tengah adalah tenaga kerja dan kurva atas adalah produksi. Data yang akan digunakan untuk proses prediksi terlihat pada Gambar 6.

$$
\begin{aligned}
& \text { Data Produksi Usaha Rakik Julidar }
\end{aligned}
$$

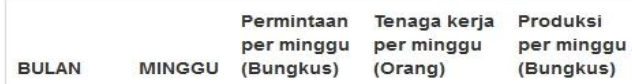

$$
\begin{aligned}
& \begin{array}{lllll}
\text { Maret } 2020 \quad 1 & 140 & 35 & 140
\end{array}
\end{aligned}
$$

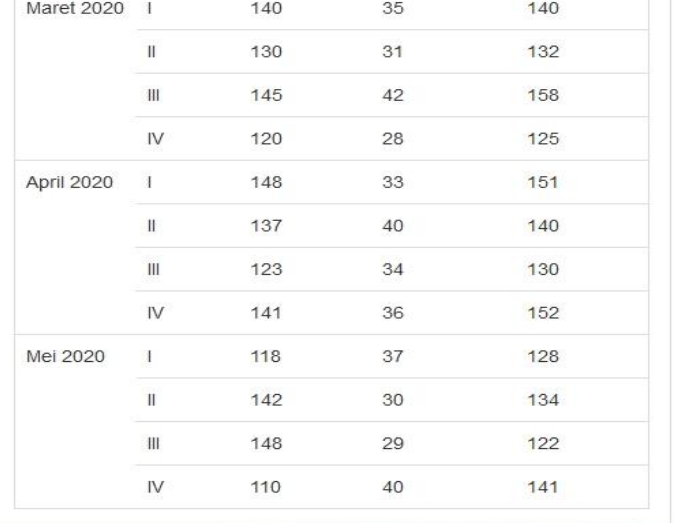

Pada Gambar 6 menampilkan data yang akan digunakan untuk proses fuzzy Tsukamoto, terdiri dari data 3 bulan mulai dari Maret sampai Mei 2020 atau selama 12 minggu produksi.

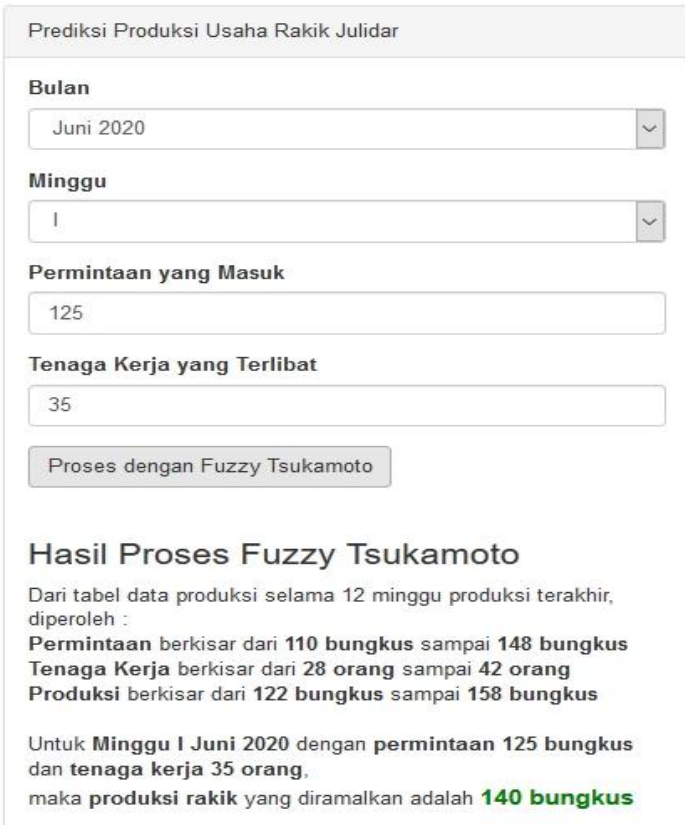

Gambar 7. Prediksi Produksi dengan Fuzzy Tsukamoto 
Proses fuzzy Tsukamoto dapat dilihat pada Gambar 7 yang merupakan proses inti dari prediksi produksi rakik, dimulai dengan pemilihan Bulan dan Minggu yang akan diprediksi, dan memasukkan jumlah permintaan dan jumlah tenaga kerja, dan proses fuzzy dilakukan, maka akan muncul jumlah produksi yang harus dipenuhi.

\section{SIMPULAN}

Setelah melakukan penganalisaan dan pengolahan terhadap data serta penerapan aplikasi prediksi produksi rakik dengan fuzzy Tsukamoto, maka dapat disimpulkan bahwa penelitian yang menghasilkan aplikasi ini sangat membantu Usaha Rakik Julidar dalam melakukan prediksi jumlah produksi rakik karena dapat menghasilkan angka produksi yang jelas.

Hasil dari penelitian ini dapat menghindari masalah permintaan yang banyak tetapi tenaga kerja sedikit atau sebaliknya, permintaan sedikit tetapi tenaga kerja berlebih, sehingga tidak optimal untuk melakukan produksi. Disamping itu, penelitian ini juga dapat membantu masalah penyaluran rakik, baik dari segi waktu dan jumlah produk.

Diharapkan adanya penelitian selanjutnya dengan menggunakan variabel fuzzy yang berbeda dan penggunaan metode inferensi yang berbeda agar mendapatkan hasil yang lebih optimal. Diharapkan juga ada penelitian lainnya tentang produk industri rumah tangga dalam rangka membantu dan memajukan UMKM di Indonesia.

\section{DAFTAR PUSTAKA}

[1] N. K. D. A. Jayanti and G. Sastrawangsa, "PEMANFAATAN TEKNOLOGI TEPAT GUNA BAGI UKM REMPEYEK," Maj. Apl. Ipteks NGAYAH, vol. 9, pp. 160-172, 2018.

[2] Araya, Jessica, and H. Susanto, "KORELASI ANTARA JUMLAH KACANG TANAH DALAM REMPEYEK DENGAN HARGANYA," Indones. Fun Sci. $J$. , vol. 1, no. 1, pp. 121-132, 2019.

[3] V. Wira and Gustati, "PROFIL INDUSTRI RUMAH TANGGA RAKIK DI KECAMATAN PAUH KOTA PADANG," J. Akunt. Manaj., vol. 10, p. 2, 2015.

[4] A. Airin et al., "FAKTORFAKTOR YANG MENGHALANGI PENJUALAN REMPEYEK," J. Pemberdaya. Masy., vol. 01, no. 01, 2019. E. Bramantyo, "PEMBERDAYAAN PEREMPUAN MELALUI PROGRAM PENDAMPINGAN SKB DI PKBM DALAM MENGEMBANGKAN

KEWIRAUSAHAAN BERBASIS POTENSI LOKAL KABUPATEN BANTUL," J. Pendidik. Luar Sekol., vol. 4, no. 3, pp. 1-11, 2015.

[6] Junaidi, A. Amir, and Hardiani, "Potensi Klaster Agroindustri Usaha Mikro Kecil dan Menengah di Provinsi Jambi," J. Perspekt. Pembiayaan dan Pembang. Drh., vol. 2, no. 1, pp. 9-20, 2014.

[7] A. Wantoro, K. Muludi, and Sukisno, "Penerapan Logika Fuzzy pada Sistem Pendukung Keputusan Penentuan Kelayakan 
Kualitas Telur Bebek," JUTIS, vol. 7, no. 1, pp. 1-6, 2019.

[8] I. Anggraeni and Y. Yanti, "Sistem Pemantauan Pertumbuhan Batita Menggunakan Metode Fuzzy Tsukamoto," Komputasi J. Ilm. Ilmu Komput. dan Mat., vol. 17, no. 1, pp. 346-353, 2020.

[9] O. E. Putra and E. L. Febrianti, "Analisa Jumlah Produksi Pada Industri Rumah Tangga Dengan Menggunakan Logika Fuzzy: Studi Kasus Ud Tempe Puji Kecamatan Bayang Kabupatern
Pesisir Selatan," Sainstek J. Sains dan Teknol., vol. 8, no. 2, p. 173, 2017.

[10] W. Ilham and N. Fajri, "PENENTUAN JUMLAH PRODUKSI TAHU DENGAN MENGGUNAKAN METODE FUZZY TSUKAMOTO PADA UKM ABADI BERBASIS WEB," J. Digit, vol. 10, no. 1, pp. 71-82, 2020.

[11] E. P. W. Mandala, "Web Programing, Project 1 epwm forum," Yogyakarta Andi, 2015. 